\title{
The Role of Social Perspective-Taking in Developing Students' Leadership Capacities
}

John P. Dugan

Loyola University Chicago, jdugan1@luc.edu

Christopher W. Bohle

Lindsey R. Woelker

Matthew A. Cooney

Follow this and additional works at: https://ecommons.luc.edu/education_facpubs

Part of the Education Commons

\section{Recommended Citation}

Dugan, J. P., Bohle, C. W., Woelker, L. R., \& Cooney, M. A. (2014). The role of social perspective-taking in developing students' leadership capacities. Journal of Student Affairs Research and Practice, 51(1), 1-15. http://dx.doi.org/10.1515/jsarp-2014-0001

This Article is brought to you for free and open access by the Faculty Publications and Other Works by Department at Loyola eCommons. It has been accepted for inclusion in Education: School of Education Faculty Publications and Other Works by an authorized administrator of Loyola eCommons. For more information, please contact ecommons@luc.edu.

\section{c) (i) $\ominus$}

This work is licensed under a Creative Commons Attribution-Noncommercial-No Derivative Works 3.0 License. (c) NASPA, 2014. 


\title{
The Role of Social Perspective-Taking in Developing Students' Leadership Capacities
}

\author{
John P. Dugan, Loyola University Chicago \\ Christopher W. Bohle, Hope College \\ Lindsey R. Woelker, St. Edward's University \\ Matthew A. Cooney, Bowling Green State University
}

\begin{abstract}
This study examined relationships between social perspective-taking (SPT) and the individual, group, and societal domains of socially responsible leadership. SPT is a higher-order cognitive skill linked to moral development and social coordination, but never empirically connected to leadership development. Analyses determined SPT has a strong direct effect on group-level leadership values and an indirect effect on societallevel leadership values. Results offer critical new insights into directionality in the social change model.
\end{abstract}

The compelling need for societal leaders and recognition of the important role higher education plays in cultivating leadership capacity stimulated substantial scholarship over the past 2 decades on how best to leverage college student leadership development (Astin \& Astin, 2000; Rosenthal, 2011). Much of this work has focused on socially responsible leadership and its application using the social change model of leadership development (Dugan, 2011). This emphasis derives largely from the social change model's identification as the most applied model in college student leadership programs (Kezar, Carducci, \& Contreras-McGavin, 2006; Owen, 2012) and the positioning of social responsibility as a critical college outcome (Association of American Colleges \& Universities, 2007).

The social change model falls within the family of relational and reciprocal leadership approaches (e.g., transformational leadership, authentic leadership, relational leadership) emphasizing self-awareness, shared responsibility, and a grounding in ethics and justice (Kezar et al., 2006; Komives \& Dugan, 2010) and composed of seven core values that cluster across individual (i.e., consciousness of self, congruence, commitment), group (e.g., collaboration, common purpose, controversy with civility), and societal (e.g., citizenship) domains (Higher Education Research Institute [HERI], 1996). Table 1 provides definitions for each of the domains and their values. These values collectively contribute to an individual's overall capacity for socially responsible leadership,

John P. Dugan, Associate Professor of Higher Education, Loyola University Chicago. Christopher W. Bohle, Associate Director of Student Life, Hope College. Lindsey R. Woelker, Assistant Director, Hilltop Leadership Development, St. Edward's University. Matthew A. Cooney, Doctoral Student, Bowling Green State University. Correspondence concerning this article should be addressed to Dugan at Jdugan1@luc.edu. 
Table 1

\section{Social Change Model Domains and Values}

\begin{tabular}{ll}
\hline Value & \multicolumn{1}{c}{$\begin{array}{c}\text { Definition } \\
\text { Individual Domain }\end{array}$} \\
\hline Consciousness of self & $\begin{array}{l}\text { General self-awareness with particular attention toward the beliefs, values, attitudes, } \\
\text { and emotions that motivate one to take action. }\end{array}$ \\
Congruence & $\begin{array}{l}\text { Thinking, feeling, and behaving with consistency, genuineness, authenticity, and } \\
\text { honesty towards others; actions are consistent with most deeply-held beliefs and } \\
\text { convictions. }\end{array}$ \\
Commitment & $\begin{array}{l}\text { The psychic energy that motivates the individual to serve and that drives the collec- } \\
\text { tive effort; implies passion, investment, and follow-through directed toward both } \\
\text { the group activity as well as its intended outcomes. }\end{array}$ \\
Group domain & $\begin{array}{l}\text { The ability to work with others effectively in a common effort; constitutes the cor- } \\
\text { nerstone value of the group leadership effort because it empowers self and others } \\
\text { through trust and shared responsibility. }\end{array}$ \\
Collaboration & $\begin{array}{l}\text { To work with shared aims and values; facilitates the group's ability to engage in col- } \\
\text { lective analysis of issues at hand and the task to be undertaken. }\end{array}$ \\
Common purpose & $\begin{array}{l}\text { Recognition of two fundamental realities of any group effort: that differences in } \\
\text { viewpoint are inevitable, and that such differences must be aired openly, but with } \\
\text { civility. }\end{array}$ \\
Occurs when one becomes responsibly connected to the community/society by \\
working for positive change interdependently with others.
\end{tabular}

Adapted from HERI (1996) and Komives et al. (2009).

which is defined as "a purposeful, collaborative, values-based process that results in positive social change" (Komives, Wagner, \& Associates, 2009, p. xii).

Despite increasing research using the social change model, attention has been disproportionately directed at understanding predictors of specific leadership values or domains as opposed to how they interact to inform one another. The lack of attention toward interactions is despite the conceptual design of the model, which suggests the values are interdependent with development in one domain influencing that of other domains (HERI, 1996). What facilitates growth between domains is largely unknown. A lack of empirical knowledge regarding the dynamic interaction across leadership domains inhibits educators' abilities to effectively target developmental interventions.

Social perspective-taking (SPT), a complex cognitive skill, may offer explanatory power in understanding the developmental interactions across leadership domains. Increasingly, scholars validate its critical role in shaping intellectual and moral development (Dey \& Associates, 2010). The broader leadership studies literature also hypothesizes SPT as an essential component of leadership (Avolio, 2010; Galinsky, Jordan, \& Sivanathan, 2008; Mumford, Zaccaro, Harding, Jacobs, \& Fleishman, 2000) and as a factor in the development of leadership-related skills (Davis, 1983; Deutsch, 2000; Galinsky, Ku, \& Wang, 2005; Johnson, 1975). Empirical connections between SPT and socially responsible leadership have yet to be made. The purpose of this research was to examine whether SPT influenced socially responsible leadership development across the individual, group, and societal domains. 


\section{What is SPT?}

Stemming largely from the social psychology literature, SPT reflects the ability to take another person's point of view and accurately infer the thoughts and feelings of others (Gehlbach, 2004; Johnson, 1975; Selman, 1980; Underwood \& Moore, 1982). SPT, also known as "perspectivetaking" or "role-taking," represents both cognitive and affective dimensions that allow an individual to empathize with another while maintaining individuality (Galinsky et al., 2005). SPT links theoretically to epistemological development and is considered a higher-order cognitive skill (i.e., associated with complex judgment, critical thinking, and problem solving particularly useful in novel situations; Gehlbach, 2004; Hoffman, 2000). As cognitive structures develop, there is a "shift in focus from an egocentric embeddedness in his [SIC one's] own point of view to a cognitive orientation in which diverse aspects of objects or social situations are simultaneously taken into account" (Hale \& Delia, 1976, p. 197).

SPT is also linked theoretically to moral development, the cognitive reorganization of thought patterns related to how one makes moral judgments based on principles of justice (Kohlberg, 1976). Moral judgment involves the incorporation of new and diverse perspectives that build onto or shift existing frameworks while also taking situational factors into account (Colby, Kohlberg, Gibbs, \& Lieberman, 1983). SPT plays a critical role in this process as moral internalization occurs through intentionally integrating new ideas as well as perspectives of others into one's moral framework, mainly through conflict resolution and negotiation (Hoffman, 2000). Kohlberg (1984) asserted that opportunities to engage in SPT during the college years were particularly influential in the realization of complex moral reasoning.

\section{SPT and Leadership}

Leadership scholars increasingly identify SPT as a key component of effective leadership (Avolio, 2010; Galinsky et al., 2008; Mumford et al., 2000). The ability to recognize alternative perspectives and infer the thoughts and feelings of others is congruent with emphases in contemporary leadership theory on self-awareness, other-directedness, and process orientations (Komives \& Dugan, 2010). Gehlbach and Brinkworth (2012) hypothesized that SPT may specifically assist positional leaders in anticipating the preferred leadership styles of followers.

SPT plays a critical role in broadening an individual's understanding of self in the context of others (Davis, Conklin, Smith, \& Luce, 1996; Galinsky et al., 2005). Understanding oneself in relation to others augments the ability to foster social bonds and decreases in-group favoritism enhancing one's overall capacity to engage effectively in group processes. Despite scholars' claims regarding the importance of SPT and empirical evidence of the wide range of leadership-related skills that it positively influences (Corcoran \& Mallinckrodt, 2000; Davis, 1983; Deutsch, 1993; Galinsky \& Ku, 2004; Galinsky \& Moskowitz, 2000; Gehlbach, 2004; Johnson, 1975; Parker \& Axtell, 2001), most linkages are conceptual. The lack of empirical evidence is an odd omission from the college student leadership literature given the importance of the collegiate environment as a developmental context for cognitive, moral, and leadership development and their potentially shared influences on one another (Evans, Forney, Guido, Patton, \& Renn, 2010; Komives, Owen, Longerbeam, Mainella, \& Osteen, 2005).

\section{Research Questions/Hypothesized Model}

The specific research question was: What is the relationship between SPT and the individual, group, and societal domains of socially responsible leadership? The hypothesized model is represented in Figure 1 and explained in detail in the following sections. 
Figure 1. Hypothesized model of influences of SPT on socially responsible leadership.

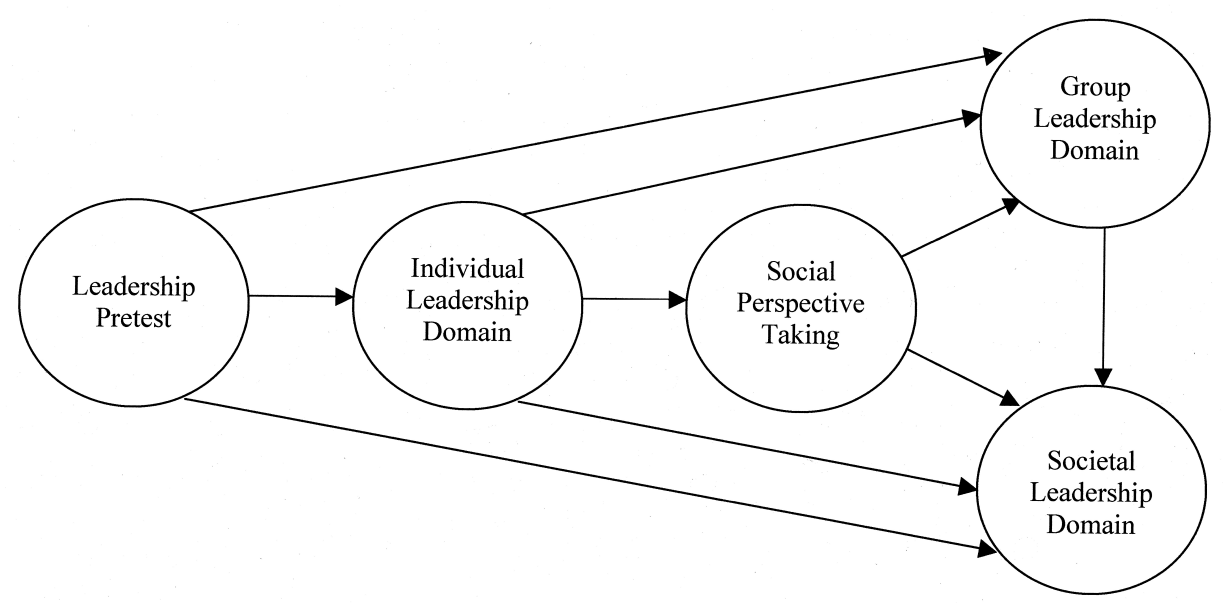

\section{Directionality Within the Social Change Model}

The social change model suggests bidirectional influences between and among all of the leadership domains (HERI, 1996). A closer reading of the explanation in the original text suggests a confounding of influences associated with leader development (i.e., increasing the capacity of individuals) and the enactment of leadership (i.e., what transpires in the process of leadership when individuals work in groups and the community). The authors justify how capacities associated with values in the individual domain undergird those in the group and societal domains and how group values support the societal domain. The explanation of inverse influences, however, leans heavily on descriptions of what may happen in the process of enacting leadership. The authors assert "feedback from the group is most likely to enhance the individual qualities of consciousness of self, commitment, and congruence when the group operates collaboratively with common purpose and accepts controversy with civility" (HERI, 1996, p. 24). Group values are not framed as capacities of the individual, but process orientations or actions that may occur as a result of being in a group process.

The hypothesized relationship between leadership domains employed in this research relies on a disentangled interpretation of the original work focused on leader development. The interpretation is consistent with other leadership literature identifying a more unidirectional approach. Day, Harrison, and Halpin (2009) emphasized the importance of cultivating individual leader capacities before moving to more complex capacities associated with group process. Research from the leadership identity development model, which examined how individuals adopt an integrated identity as a relational leader, provides evidence of a more sequential process reflective of an evolving understanding of self and others that moves from dependence toward interdependence (Komives et al., 2005).

\section{Pretest Influences}

The hypothesized model controlled for precollege leadership capacity to better examine the specific effects of the college years on leadership development. Prior research on socially responsible leadership demonstrates the strong influences of precollege knowledge and experiences in shaping leadership development during college (Dugan et al., 2011; Dugan, Kodama, \& Gebhardt, 2012; 
Dugan \& Komives, 2010). Direct effects were hypothesized between precollege leadership capacity and each of the leadership domains.

\section{Influence of Individual Domain on SPT}

As a higher order cognitive skill deeply connected to moral development, SPT requires selfawareness, clarity of personal values, and congruence between values and personal behaviors. If these individual skills are underdeveloped, there is a higher likelihood for inaccurate SPT, which may lead to social miss-coordination and overempathizing that results in individuals unnecessarily deferring their needs or presuming the needs of others (Epley, Caruso, \& Bazerman, 2004; Galinsky et al., 2005). The individual leadership domain values of consciousness of self, congruence, and commitment are hypothesized as having a direct effect on SPT.

\section{Influence of SPT on Group and Societal Domains}

Researchers linked SPT with an increased capacity for general social skills, which are defined as abilities associated with understanding people and the interconnectedness of organizations and society (Zaccaro, Gilbert, Thor, \& Mumford, 1991). General social skills positively affected by SPT include listener-focused speech (Hale \& Delia, 1976), moral decision-making (Hoffman, 2000; Kohlberg, 1976; Mason \& Gibbs, 1993), altruism/selflessness (Batson, Klein, Highberger, \& Shaw, 1995; Eisenberg \& Miller, 1987), and helping behaviors (Cialdini, Brown, Lewis, Luce, \& Neuberg, 1997; Davis 1983). Galinsky et al. (2005) described perspective-taking as "a device of social coordination, helping to cement and form social bonds" (p. 112). The formation of these social bonds as a means of social coordination acts as a critical component for the development of other group-related capacities. SPT has been shown to positively influence interpersonal functioning, decrease interpersonal aggression and social dysfunction, enhance compassion and sympathy, increase positively functioning relationships, improve cooperation, augment conflict resolution skills, reduce prejudicial attitudes or behaviors, and cultivate the capacity for psychological closeness (Cialdini et al., 1997; Corcoran \& Mallinckrodt, 2000; Davis, 1983; Deutsch, 1993; Galinsky \& Ku, 2004; Galinsky \& Moskowitz, 2000; Gehlbach, 2004; Johnson, 1975; Parker \& Axtell, 2001; Pickett, Gardner, \& Knowles, 2004). Given the positive effect of SPT on both social skills and social coordination in prior research, it was hypothesized to have both strong direct and indirect effects on the application of individual leadership values in the group and societal domains.

\section{Methods}

This research used data from the Multi-Institutional Study of Leadership (MSL), an international research program examining the effects of higher education on college students' capacities for socially responsible leadership, and employed a quantitative, cross-sectional design with data collected during spring 2009.

\section{Sampling Strategy}

Data collection relied on a two-part sampling strategy. Institutional recruitment was solicited via professional association networks and direct mailings. A total of 101 U.S. institutions representing 31 states and the District of Columbia participated. Schools were both public (48\%) and private (52\%). Institutional size included: $24 \%$ enrolled 3,000 or fewer undergraduates, $37 \%$ enrolled between 3,001 and 10,000 undergraduates, and 38\% reported enrollments exceeding 10,000 undergraduates. Carnegie types included 43\% extensive and intensive research institutions, 36\% master's institutions, $19 \%$ baccalaureate institutions, and $2 \%$ associates institutions. 
Student-level data represented simple random samples for institutions with total undergraduate enrollments exceeding 4,000 students. Sample sizes were calculated using a desired confidence level of $95 \%$, a confidence interval of \pm 3 , and oversampling at a rate of $70 \%$. Institutions with total undergraduate enrollments of less than 4,000 students conducted full population samples.

The final sample reflected a $34 \%$ response rate and was reduced to only include seniors to better gauge perceived development over time. The total number of participants was 13,289. The gender distribution was 36\% men and 64\% women. Twenty-four percent of participants identified as Students of Color, and the mean age was 24 years old.

\section{Instrument and Variables}

The conceptual framework for the MSL survey instrument employed an adapted version of Astin's (1991) college impact model that included a cross-sectional design in which precollege data were collected using retrospective questions. Appendix A provides descriptive statistics, factor loadings, and reliability estimates for all measures. Socially responsible leadership was measured using an adapted version of the Socially Responsible Leadership Scale (SRLS; Tyree, 1998). The SRLS is comprised of eight separate scales each measuring one of the seven values associated with the social change model and an additional scale measuring capacity to navigate change. The SRLS demonstrates strong reliability and validity as evidenced in its performance in numerous studies and significant pilot testing prior to use with the MSL (Dugan, Komives, \& Associates, 2009).

The original SRLS was modified in a number of ways. First, change in the original conceptualization of the model reflected "the ultimate goal of the creative process of leadership-to make a better world and a better society for self and others" (HERI, 1996, p. 21) and was designed as a purpose of the model, not a leadership capacity in and of itself. The Change Scale in the SRLS was designed to measure comfort with transition, making it even less congruent with the original conceptualization of the model and therefore was eliminated.

Second, confirmatory factor analyses (CFA) using structural equation modeling (SEM) indicated that the Common Purpose and Collaboration Scales did not measure unique constructs, so the Common Purpose Scale was also removed. Finally, standard data reduction techniques allowed the total number of items across all scales to be reduced to 34 . The final model was comprised of six values across the three domains: individual (i.e., Consciousness of Self, Congruence, Commitment), group (i.e., Collaboration, Controversy with Civility), and societal (i.e., Citizenship). CFA results indicated strong model fit statistics for measurement at the value level, domain level, or as a single construct representing one's overall capacity for socially responsible leadership (Dugan et al., 2009). The domain level was employed in this research.

Participants responded to the SRLS items on a continuum from strongly disagree (1) to strongly agree (5). The reliability estimates were .91 on the individual domain, .87 on the group domain, and .88 on the societal domain. A retrospective pretest capturing students' precollege leadership capacity employed the same response continuum. The 4-item composite measure serves as a general assessment of leadership and was confirmed using CFA techniques and yielded a reliability estimate of .69 , which was just below the typical threshold for interpretation of reliability but suitable for use as a control measure (Hair, Anderson, Tatham, \& Black, 1998).

Davis's (1983) Perspective-Taking Scale from the Interpersonal Reactivity Index was adapted for use in this study. The original 7-item composite measure was reduced through CFA techniques to a 5-item measure. Participants responded using a continuum ranging from does not describe me well (1) to describes me very well (5). Reliability estimates for use with this sample were .85 . 


\section{Analytic Approach}

To answer the proposed research questions, Anderson and Gerbing's (1988) two-step approach to testing SEM models was employed. Analyses first assessed the fit of an oblique (i.e., correlated factors), five-factor CFA model with the full sample and then the full, five-factor path model. For each of the above analyses results were bootstrapped using Bentler's (1995) rule of roughly 10 observations for each estimated model parameter and a resampling fraction of 8\%.

\section{Limitations}

Three key limitations should inform readers' interpretations of results from this research. First, scholars stress the importance of longitudinal designs and use of any form of quasi-pretest measure in cross-sectional research is advised to reduce limitations (Terenzini, 1994). This study employed a retrospective pretest in which participants were asked to reflect back to what they were like prior to college. Cross-sectional designs are actually recommended for use in leadership research as it aids in limiting negative influences associated with response shift bias (Howard, 1980; Howard \& Dailey, 1979). Time-elapsed longitudinal designs presume the same standard for measurement at both time points. In cases where there are underlying cognitive dimensions to the measures, this assumption may not be tenable as shifts in meaning-making between time points may alter the internalized scale, which results in skewed data and an imprecise measurement of actual gains. Scholars recommend the use of retrospective designs that avoid then/now formatting in capturing precollege data.

Second, the removal of the Common Purpose Scale given its lack of statistical differentiation from the Collaboration Scale deviates from the original conceptualization of the social change model and merits further exploration. An examination of the definitional parameters for common purpose and collaboration in the original work seems to support the statistical finding as common purpose is defined as a function of collaboration and characteristic of the group, not necessarily a capacity of individuals within the group (HERI, 1996). Finally, multilevel modeling was not used despite the presence of nested data, because prior analyses employing these measures did not yield meaningful between-school effects (Dugan et al., 2012; Owen, 2008) and interclass correlations were well below the stated thresholds for multilevel techniques (Lee, 2000).

\section{Results}

Bootstrapping with reasonably sized samples ensured that the large sample sizes were not distorting the results of model fitting. Results are presented using data from the full sample given the bootstrapping did not reveal significant slippage in model fit statistics. Analyses began by assessing the fit of a one-factor CFA with the total sample of 13,289 participants $\left(\chi^{2}=94,720.29 ; d f=860\right)$, which yielded poor model fit statistics $(\mathrm{RMSEA}=.113, \mathrm{SRMR}=.078, \mathrm{CFI}=.873, \mathrm{NNFI}=.866)$. Next, a five-factor CFA comprising 43-items and 96 estimated parameters (43 loadings, 43 unique errors, and 10 factor intercorrelations) was calculated. The five-factor CFA $\left(\chi^{2}=46,387.20 ; d f=\right.$ $850)$ improved significantly upon the one-factor model and fit the data well by all standards (RM$\mathrm{SEA}=.071, \mathrm{SRMR}=.053, \mathrm{CFI}=.950, \mathrm{NNFI}=.947)$ as did the corresponding five-factor latent variable path model $\left(\chi^{2}=46,427.80 ; d f=851\right.$, RMSEA $=.071, \mathrm{SRMR}=.053, \mathrm{CFI}=.950, \mathrm{NNFI}=$ .947). Figure 2 provides an updated model with path coefficients and the variance explained for all endogenous variables in the model. Based on Cohen's (1988) effect size parameters, the path from the pretest to the individual domain demonstrated a large effect size $(\beta=.52)$, while the effect from the pretest to the group domain was trivial $(\beta=.05)$ and the path to the societal domain yielded a small effect $(\beta=.20)$. The path from the individual domain to the group domain demonstrated a 
Figure 2. Final model for influences of SPT on socially responsible leadership.

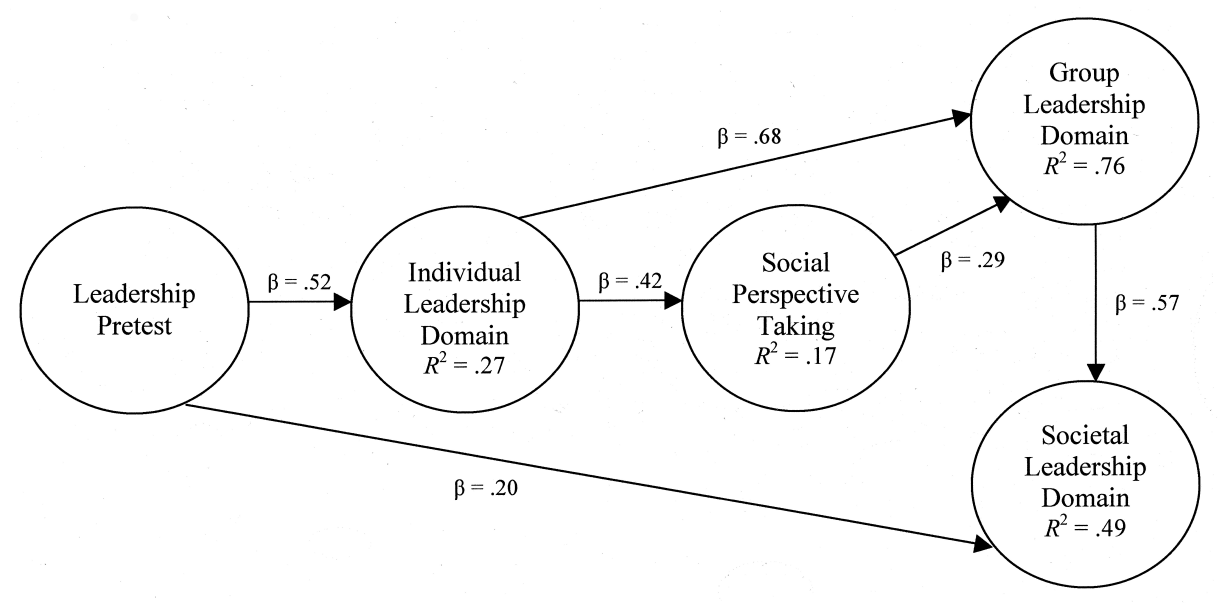

large effect size $(\beta=.68)$, while the effect from the individual to the group domain was trivial $(\beta=$ $-.01)$ and the path to SPT yielded a medium effect $(\beta=.42)$. SPT demonstrated a medium effect size $(\beta=.29)$ on the path to the group domain, but the effect to the societal domain was trivial $(\beta=$ $.03)$. The path from the group domain to the societal domain demonstrated a large effect $(\beta=.57)$. The multiple squared correlation for endogenous variables reflected a large effect for the individual $\left(R^{2}=.27\right)$, group $\left(R^{2}=.76\right)$, and societal $\left(R^{2}=.49\right)$ domains and a medium effect for SPT $\left(R^{2}=.17\right)$.

\section{Discussion}

Results from this research offer unique findings that frame the importance of SPT and extend the understanding of how domains within the social change model influence one another. First, analyses revealed that after controlling for students' precollege leadership capacity, SPT emerged as an important mediator of individual leadership values (i.e., consciousness of self, congruence, commitment) on group leadership values (i.e., collaboration, controversy with civility). The indirect pathway from individual to group domains as mediated by SPT was of greater strength than the direct pathway between domains. SPT also demonstrated an indirect effect on the societal leadership domain. These findings affirm the social psychology literature suggesting SPT is a powerful tool for social coordination (Galinsky et al., 2005) and extend the benefits of social coordination to leadership development. Results also offer empirical confirmation for the conceptual assertions that SPT is a key component of effective leadership and are the first to empirically link SPT with socially responsible leadership.

Second, SPT did not demonstrate a direct effect on the societal domain, which is intriguing. One would assume that the ability to take others' perspectives would directly influence the degree to which "an individual becomes responsibly connected to the community and the society" (HERI, 1996, p. 23). This finding situates group-level leadership values as strong regulators of whether a person demonstrates citizenship capacity. Perhaps group experiences build the capacities for effective collaboration and navigation of conflict, in turn augmenting individuals' efficacy for engaging at a broader societal level. This hypothesis would support existing literature suggesting the powerful role that positive group experiences can have on overall leadership development (Komives et al., 2005). Alternatively, the effective use of group-level leadership values may foster the types of meaningful social linkages necessary for individuals to engage more interdependently with one another. 
Finally, results from this research offer new insights into the social change model and the ways in which value domains interact with one another. Consistent with prior research on socially responsible leadership, students' precollege knowledge, attitudes, and behaviors were significant predictors of their overall leadership development (Dugan, 2011). The analytic approach employed in this research determined that pretest influences were largely directed toward the individual leadership domain with no direct effect on the group domain and only a small effect on the societal domain. The lack of a direct effect on the group domain situates the college context as a critical time for developing leadership capacities in this area. The importance of developing group leadership capacities during college is consistent with Komives et al.'s (2005) leadership identity development theory, which highlighted significant cognitive and psychosocial shifts during college that resulted in increasingly relational leadership orientations.

The pretest demonstrated a small, direct effect on the societal leadership domain, while the individual leadership domain lacked any direct effect. The small, direct effect between the pretest and societal domain could represent residual influences regarding what students believe it means to be engaged in one's community. These beliefs may reflect adopted versus internalized values from parents or other authority figures regarding the important connections between leadership and community involvement. For the majority of students, the most significant effect on their citizenship capacity will be derived through indirect effects of developing leadership capacities associated with the group domain in the college environment.

\section{The Value of Cultivating SPT}

\section{Implications}

Findings suggest that educators committed to developing students' capacities for socially responsible leadership should direct more attention to SPT. Increasing students' abilities to effectively engage in SPT would facilitate the process of connecting individual leadership values with group leadership values and indirectly influence students' capacities for citizenship.

Research substantiates gains in SPT associated with a variety of educational interventions including community service, interactions with faculty outside the classroom, and exposure to less popular viewpoints (Dey \& Associates, 2010). Educators should consider how they can embed these experiences as intentional training for SPT in leadership development programs. In many ways, the development of SPT offers a much more concrete learning outcome than more ambiguous capacities like collaborating and navigating controversy with civility. Gehlbach and Brinkworth (2012) identified an empirical taxonomy of specific strategies that individuals used in the process of SPT and included both inferential strategies (e.g., considering the present context, projection) and information cultivation strategies (e.g., emotion regulation, increasing modalities). Gehlbach, Brinkworth, and Wang (2012) extended this work by also identifying motivational factors (e.g., prosocial goals, intrinsic interest) influencing whether a person actually decided to use SPT.

The strategies and motivational factors associated with SPT offer a foundation from which to build specific experiences that effectively integrate SPT and leadership development. Increasing content knowledge and skill acquisition associated with emotional regulation, a key information cultivation strategy associated with SPT, may be a way to increase SPT as well as bridge individual and group level leadership capacities. Leadership experiences often explore self-awareness and values clarification, but to what degree do we adequately address the manifestation of this awareness in social contexts? Shankman and Allen's (2008) text and collective resources associated with emotional intelligence and leadership offer exceptional tools for engaging in this work. Educators should consider how they aid students in addressing the ways in which their emotions surface both as a useful tool for social connection across differences as well as potential inhibitors. 
Similarly, leadership educators should consider how to build inferential strategies such as recognizing contextual cues that inform varying perspectives. Given the connection between moral development and SPT, the introduction of ill-structured problems (i.e., issues for which there are no right answers and often competing values) may serve as a powerful vehicle for increasing both cognitive reasoning and empathy. Ill-structured problems could be introduced as case studies, debates, or simulations related to leadership topics in workshops, retreats, or a variety of training experiences. The goal of these exercises is not to seek a common resolution or agreement, but to elicit varying perspectives on the issue. Once different perspectives are surfaced, educators should build skills associated with understanding how individuals arrive at their opinions, the contextual influences that inform them (e.g., life history, social status, environment, values), and the ability to integrate agreement/disagreement with empathy.

In essence the process of group engagement around the ill-structured issue offers the substance of the exercise in lieu of the issue itself. As students build increasing aptitude with inferential strategies, educators should begin embedding opportunities for sociocultural conversations, a highimpact learning pedagogy associated with gains in both leadership efficacy and leadership capacity (Dugan \& Komives, 2010; Dugan et al., 2012). The move toward dialogue introduces deeper personal associations with ill-structured problems that often exist at more systemic levels.

\section{Addressing Directionality of the Social Change Model}

Findings related to directionality in the social change model also offer insights into ways that leadership program content might be structured to best leverage student learning. Results suggest the critical importance of developmental sequencing in the design and delivery of leadership programs. Developmental sequencing does not suggest that educational interventions should avoid introducing students to all three domains associated with the social change model simultaneously, but that educators should use caution as students may not possess the developmental readiness necessary to fully benefit from complex experiences focused on citizenship development if they have not sufficiently developed individual and group-level capacities.

Dugan and Komives (2010) identified specific predictors of leadership development across all eight values associated with the social change model. Findings provide guidance as to the best intervention approaches for the individual and group domains of socially responsible leadership. Sociocultural conversations with peers, efficacy-building experiences, faculty mentoring, and community service demonstrated positive effects on both individual and group values. Long duration leadership training programs had a negative effect on individual leadership value, while moderate duration leadership training and participation in student organizations had a positive effect on the group values.

In their research on accelerating leadership development, Day et al. (2009) stressed the riskiness of overestimating developmental readiness or prematurely inflating the complexity of educational interventions given the potential to cause developmental retreat (i.e., reversion to less complex meaning making typically due to excess challenge). Critical questions should be asked regarding the appropriateness and potential negative effects for communities when developmentally unprepared students are thrust into broader social contexts and asked to engage in social change. Scholars in the area of service learning articulate well the problematic nature of using social contexts as laboratories for student learning (Butin, 2006, 2007; Morton, 1995; Rhoads, 1997). Educators should be aware of varying developmental levels present among participants and target both content and context accordingly. Central to this is the need for group experiences in which students can experiment with the application of individual leadership values and cultivate group capacities. 
Applications of sequencing socially responsible leadership development can be seen in both curricular and cocurricular learning experiences. For example, content should move from individual awareness to group process to community/collective considerations, and this may or may not happen within a single resource. Books such as The Leadership Challenge (Kouzes \& Posner, 2012) and Strengths Based Leadership (Rath \& Conchie, 2008), which focus at least initially on behaviors and leader roles, may be most appropriate at early stages of the educational process. These texts can provide powerful heuristics for self-awareness that offer more concrete and individual insights before moving into group level and process orientations. Alternatively, books like Leadership for a Better World (Komives et al., 2009), Leadership Without Easy Answers (Heifetz, 1994), and Learning as a Way of Leading (Preskill \& Brookfield, 2009) offer complex treatments of group level processes, social systems, and the complexity of leadership perhaps more appropriate when introduced later in the learning process. A similar pattern might be recommended for the use of service-related pedagogies in the delivery of leadership education that mirror increasing complexity from charitybased initiatives through service-learning to participatory action research.

\section{Future Research Considerations}

Findings from this study offer a rich base from which to build future research. Consistent with Pascarella's (2006) call for increased conditional analyses in college impact research, future studies should explore the degree to which the model identified here holds across student subpopulations. Of particular importance may be the examination of gender-based differences given SPT reflects a higher-order cognitive skill and ample evidence exists supporting differences in cognitive development based on gender (Evans et al., 2010). Research is also needed that extends the general knowledge of SPT examining the differential effects of accurate versus inaccurate attempts to engage in SPT on students' motivations to use the behaviors in the future. Qualitative designs may be particularly useful for exploring this along with developmental thresholds in SPT. Finally, additional research is needed that further unpacks the relationship between SPT and leadership development. What role does leadership efficacy, a potent predictor of socially responsible leadership (Dugan, 2011), play when considered in the context of SPT? What collegiate experiences and pedagogical approaches associated with leadership development predict increases in students' SPT above and beyond the broad interventions (i.e., community service, interactions with faculty outside the classroom, and exposure to less popular viewpoints) identified by Dey and Associates (2010)?

\section{Conclusion}

Scholars have asserted the powerful role SPT plays in social coordination (Avolio, 2010; Davis, 1983; Galinsky et al., 2005; Galinsky et al., 2008; Gehlbach, 2004; Mumford et al., 2000). Dey and Associates (2010) argue that "college graduates must be prepared to work and live in a global context where being well-informed about and open to the perspectives of others is critical" (p. 21). Building on these claims, this research examined the influences of SPT on college student leadership development and identified SPT as an important mediator between individual and group leadership capacities. These findings offer empirical confirmation of the significance of SPT and situate it as a critical predictor of socially responsible leadership. Furthermore, this research offered new evidence regarding directionality between domains of the social change model positioning group leadership capacities as a critical leverage point in the development of socially responsible leadership. Collectively, this research significantly advances the understanding of the social change model as well as its application in leadership education. 


\section{References}

Anderson, J. C., \& Gerbing, D. W. (1988). Structural equation modeling in practice: A review and recommended two-step approach. Psychological Bulletin, 103(3), 411-423.

Association of American Colleges \& Universities. (2007). College learning for the new global century. Washington, DC: Author. Astin, A. W. (1991). Assessment for excellence. New York, NY: American Council on Education/Macmillan.

Astin, A. W., \& Astin, H. S. (2000). Leadership reconsidered. Battle Creek, MI: W. K. Kellogg Foundation.

Avolio, B. J. (2010). Pursuing authentic leadership development. In N. Nohria \& R. Khurana (Eds.), Handbook of leadership theory and practice (pp. 739-768). Boston, MA: Harvard Business School Press.

Batson, C. D., Klein, T. R., Highberger, L., \& Shaw, L. L. (1995). Immorality from empathy induced altruism: When compassion and justice conflict. Journal of Personality \& Social Psychology, 68(6), 1042-1054.

Bentler, P. M. (1995). EQS: Structural equations program manual. Encino, CA: Multivariate Software.

Butin, D. W. (2006). The limits of service-learning in higher education. Review of Higher Education, 29(4), 473-498.

Butin, D. W. (2007). Justice-learning: Service-learning as justice-oriented education. Equity \& Excellence in Education, 40(2), $1-7$.

Cialdini, R. B., Brown, S. L., Lewis, B. P., Luce, C., \& Neuberg, S. L. (1997). Reinterpreting the empathy-altruism relationship: When one into one equals oneness. Journal of Personality \& Social Psychology, 73(3), 481-494.

Cohen, J. (1988). Statistical power analysis for the behavioral sciences. Hillsdale, NJ: Erlbaum.

Colby, A., Kohlberg, L., Gibbs, J., \& Lieberman, M. (1983). A longitudinal study of moral judgment. Monographs of the Society for Research in Child Development, 48(1/2), 1-124.

Corcoran, K. O., \& Mallinckrodt, B. (2000). Adult attachment, self-efficacy, perspective taking, and conflict resolution. Journal of Counseling \& Development, 78(4), 473-483.

Davis, M. H. (1983). Measuring individual differences in empathy: Evidence for a multidimensional approach. Journal of Personality and Social Psychology, 44(1), 113-126.

Davis, M. H., Conklin, L., Smith, A., \& Luce, C. (1996). Effect of perspective taking on the cognitive representation of persons: A merging of self and other. Journal of Personality \& Social Psychology, 70(4), 713-726.

Day, D. V., Harrison, M. M., \& Halpin, S. M. (2009). An integrative approach to leader development. New York, NY: Routledge.

Deutsch, M. (1993). Educating for a peaceful world. American Psychologist, 48(5), 510-517.

Deutsch, M. (2000). Cooperation and competition. In M. Deutsch \& P. T. Coleman (Eds.), Handbook of conflict resolution (1st ed.; pp. 21-40). San Francisco, CA: Jossey-Bass.

Dey, E. L., \& Associates. (2010). Engaging diverse viewpoints. Washington, DC: Association of American Colleges \& Universities.

Dugan, J. P. (2011). Research on college student leadership. In S. R. Komives, J. P. Dugan, J. E. Owen, W. Wagner, C. Slack, \& Associates, Handbook for student leadership development (pp. 59-84). San Francisco, CA: Jossey-Bass.

Dugan, J. P., Bohle, C. W., Gebhardt, M., Hofert, M., Wilk, E., \& Cooney, M. A. (2011). Influences of leadership program participation on students' capacities for socially responsible leadership. Journal for Student Affairs Research and Practice, 48(1), 65-84.

Dugan, J. P., Kodama, C. M., \& Gebhardt, M. C. (2012). Race and leadership development among college students: The additive value of collective racial esteem. Journal of Diversity in Higher Education, 5(3), 174-189.

Dugan, J. P., \& Komives, S. R. (2010). Influences on college students' capacity for socially responsible leadership. Journal of College Student Development, 51(5), 525-549.

Dugan, J. P., Komives, S. R., \& Associates. (2009). Multi-Institutional Study of Leadership 2009. College Park, MD: National Clearinghouse for Leadership Programs.

Eisenberg, N., \& Miller, P. A. (1987). The relation of empathy to prosocial and related behaviors. Psychological Bulletin, 101(1), 91-119.

Epley, N., Caruso, E. M., \& Bazerman, M. H. (2006). When perspective taking increases taking: Reactive egoism in social interaction. Journal of Personality and Social Psychology, 91(5), 872-889.

Evans, N., J. Forney, D. S., Guido, F. M., Patton, L. D., \& Renn, K. A. (2010). Student development in college (2nd ed.). San Francisco, CA: Jossey-Bass.

Galinsky, A. D., Jordan, J., \& Sivanathan, N. (2008). Harnessing the power to capture leadership. In J. B. Ciulla (Ed.), Leadership at the crossroads (pp. 283-300). Westport, CT: Praeger.

Galinsky, A. D., \& Ku, G. (2004). The effects of perspective-taking on prejudice: The moderating role of self-evaluation. Personality and Social Psychology Bulletin, 30(5), 594-604.

Galinsky, A. D., Ku, G., \& Wang, C. S. (2005). Perspective-taking and self-other overlap: Fostering social bonds and facilitating social coordination. Group Processes \& Intergroup Relations, 8(2), 109-124.

Galinsky, A. D., \& Moskowitz, G. B. (2000). Perspective-taking: Decreasing stereotype expression, stereotype accessibility, and in-group favoritism. Journal of Personality and Social Psychology, 78(4), 708-724.

Gehlbach, H. (2004). A new perspective on perspective taking: A multidimensional approach to conceptualizing an aptitude. Educational Psychology Review, 16(3), 207-234.

Gehlbach, H., \& Brinkworth, M. E. (2012). The social perspective taking process: Strategies and sources of evidence in taking another's perspective. Teachers College Record, 114(1), 1-29.

Gehlbach, H., Brinkworth, M. E., \& Wang, M. (2012). The social perspective taking process: What motivates individuals to take another's perspective? Teachers College Record, 114(1), 1-29.

Hair, J. F., Anderson, R. E., Tatham, R. L., \& Black, W. C. (1998). Multivariate data analysis (5th ed.). Upper Saddle River, NJ: Prentice Hall.

Hale, C. L., \& Delia, J. G. (1976). Cognitive complexity and social perspective taking. Communication Monographs, 43(3), 195-203. 
Heifetz, R. A. (1994). Leadership without easy answers. Cambridge, MA: Harvard University Press.

Higher Education Research Institute. (1996). A social change model of leadership development. College Park, MD: National Clearinghouse for Leadership Programs.

Hoffman, M. L. (2000). Empathy and moral development. New York, NY: Cambridge University Press.

Howard, G. S. (1980). Response shift bias: A problem in evaluating interventions with pre/post self-reports. Evaluation Review, 4(1), 93-106.

Howard, G. S., \& Dailey, P. R. (1979). Response-shift bias: A source of contamination in self-report measures. Journal of Applied Psychology, 64(2), 144-150.

Johnson, D. W. (1975). Cooperativeness and social perspective taking. Journal of Personality and Social Psychology, 31(2), $241-244$.

Kezar, A. J., Carducci, R., \& Contreras-McGavin, M. (2006). Rethinking the "L" word in higher education. ASHE Higher Education Report, 31(6). San Francisco, CA: Jossey-Bass.

Kohlberg, L. (1976). Moral stages and moralization: The cognitive-developmental approach. In T. Lickona (Ed.), Moral development and behavior (pp. 31-53). New York, NY: Holt.

Kohlberg, L. (1984). Essays on moral development. San Francisco, CA: Harper.

Komives, S. R., \& Dugan, J. P. (2010). Contemporary leadership theories. In R. A. Couto (Ed.), Handbook of political and civic leadership (pp. 109-125). Thousand Oaks, CA: SAGE.

Komives, S. R., Owen, J. E., Longerbeam, S., Mainella, F. C., \& Osteen, L. (2005). Developing a leadership identity: A grounded theory. Journal of College Student Development, 46(6), 593-611.

Komives, S. R., Wagner, W., \& Associates. (2009). Leadership for a better world. San Francisco, CA: Jossey-Bass.

Kouzes, J. M., \& Posner, B. Z. (2012). The leadership challenge. San Francisco, CA: Jossey-Bass.

Lee, V. A. (2000). Using hierarchical linear modeling to study social contexts: The case of school effects. Educational Psychologist, 35(2), 125-141.

Mason, G. M., \& Gibbs, J. C. (1993). Social perspective taking and moral judgment among college students. Journal of Adolescent Research, 8(1), 109-123.

Morton, K. (1995). The irony of service: Charity, project, and social change in service-learning. Michigan Journal of Community Service-Learning, 2(1), 19-32.

Mumford, M. D., Zaccaro, S. J., Harding, F. D., Jacobs, T. O., \& Fleishman, E. A. (2000). Leadership skills for a changing world: Solving complex social problems. Leadership Quarterly, 11(1), 11-35.

Owen J. E. (2008). Towards an empirical typology of collegiate leadership development programs: Examining effects on student self-efficacy and leadership for social change. Dissertation Abstracts International, 69(09). (AAT 3324779)

Owen, J. E. (2012). Findings from the Multi-Institutional Study of Leadership Institutional Survey. College Park, MD: National Clearinghouse for Leadership Programs.

Parker, S. K., \& Axtell, C. M. (2001). Seeing another viewpoint: Antecedents and outcomes of employee perspective-taking. Academy of Management Journal, 44(6), 1085-1100.

Pascarella, E. T. (2006): How college affects students: Ten directions for future research. Journal of College Student Development, 47(5), 508-520.

Pickett, C. L., Gardner, W., \& Knowles, M. (2004). Getting a cue: The need to belong and enhanced sensitivity to social cues. Personality and Social Psychology Bulletin, 30(9), 1095-1107.

Preskill, S., \& Brookfield, S. D. (2009). Learning as a way of leading: Lessons from the struggle for social justice. San Francisco, CA: Jossey-Bass.

Rath, T., \& Conchie, B. (2008). Strengths based leadership. New York, NY: Gallup Press.

Rhoads, R. A. (1997). Community service and higher education. New York, NY: State University of New York Press.

Rosenthal, S. A. (2011). National leadership index 2011. Cambridge, MA: Center for Public Leadership, Harvard University.

Selman, R. L. (1980). The growth of interpersonal understanding. New York, NY: Academic Press.

Shankman, M. L., \& Allen, S. J. (2008). Emotionally intelligent leadership. San Francisco, CA: Jossey-Bass.

Terenzini, P. T. (1994). Assessment with open eyes: Pitfalls in studying student outcomes. In J. S. Stark \& A. Thomas (Eds.), Assessment and program evaluation (pp. 523-535). Needham Heights, MA: Simon \& Schuster.

Tyree, T. M. (1998). Designing an instrument to measure socially responsible leadership using the social change model of leadership development. Dissertation Abstracts International, 59(06), 1945. (AAT 9836493)

Underwood, B., \& Moore, B. (1982). Perspective-taking and altruism. Psychological Bulletin, 91(1), 143-173.

Zaccaro, S. J., Gilbert, J., Thor, K. K., \& Mumford, M. D. (1991). Leadership and social intelligence: Linking social perceptiveness and behavioral flexibility to leader effectiveness. Leadership Quarterly, 2(4), 317-331. 
Appendix A

Descriptives, Reliabilities, and Factor Loadings for all Scales

LEADERSHIP PRETEST
I valued opportunities to contribute to my community
My behaviors reflected my beliefs
I held myself accountable for responsibilities I agreed to
I enjoyed working with others toward common goals

\section{INDIVIDUAL LEADERSHIP VALUES DOMAIN}

I am able to articulate my priorities

I am usually self-confident

I know myself pretty well

I could describe my personality

I can describe how I am similar to other people

I am comfortable expressing myself

My behaviors are congruent with my beliefs

It is important to me to act on my beliefs

My actions are consistent with my values

Being seen as a person of integrity is important to me

My behaviors reflect my beliefs

I am willing to devote time and energy to things that are important to me

I stick with others through difficult times

I am focused on my responsibilities

I can be counted on to do my part

I follow through on my promises

I hold myself accountable for responsibilities I agree to

\section{GROUP LEADERSHIP VALUES DOMAIN}

I am seen as someone who works well with others

I can make a difference when I work with others on a task

I actively listen to what others have to say

I enjoy working with others toward common goals
M SD Factor Chronbach

Loading* $\alpha^{* *}$

3.99

.58

.69

.688

.599

.564

.543

4.20

.43

.91

.620

.465

.614

.560

.498

.549

.682

.627

.683

.587

.672

.664

.564

.623

.634

.633

.683

4.15

.43

.87 
Others would describe me as a cooperative group member

My contributions are recognized by others in the groups I belong to

I am open to others' ideas

I value differences in others

Hearing differences in opinions enriches my thinking

I respect opinions other than my own

I share my ideas with others

\section{SOCIETAL LEADERSHIP VALUES DOMAIN}

I believe I have responsibilities to my community

I work with others to make my communities better places

I participate in activities that contribute to the common good

I value opportunities that allow me to contribute to my com-

munity

It is important to me that I play an active role in my communities

I believe my work has a greater purpose for the larger community

\section{SOCIAL PERSPECTIVE TAKING}

Before criticizing someone, I try to imagine how I would feel in their place

When I'm upset at someone, I usually try to "put myself in their shoes"

I try to understand friends better by imagining how things look from their perspective

I try to look at everybody's side of a disagreement before I make a decision 